\title{
Crónica de la jurisprudencia europea sobre igualdad (de 1/9/2019 a 31/8/2020)
}

\author{
Chronicle of the European case law on equality \\ (from $1 / 9 / 2019$ to $31 / 8 / 2020$ )
}

\author{
JEAN JACQMAIN \\ Profesor Jubilado de la Universidad Libre de Bruselas \\ Traducción de José Fernando Lousada Arochena ${ }^{* *}$ \\ Magistrado especialista del Orden Social del Tribunal \\ Superior de Justicia de Galicia, profesor asociado de Derecho \\ Procesal de la Universidad de A Coruña. \\ María Gema Quintero Lima*** \\ Profesora titular de Derecho del Trabajo y de la Seguridad \\ Social de la Universidad Carlos III de Madrid. \\ Juan Alberto Tormos Pérez ${ }^{* * *}$ \\ Doctor en Derecho. Departamento de Derecho del Trabajo y \\ de la Seguridad Social de la Universitat de València \\ Belén García Romero ${ }^{* * * *}$ \\ Profesora titular de Derecho del Trabajo y de la Seguridad \\ Social de la Universidad de Murcia
}

doi: https://doi.org/10.20318/femeris.2021.6144

*El texto original en francés se publicó en Journal de Droit Européen, 2020, pp. 415 y ss. La crónica comprende decisiones del Tribunal de Justicia de la Unión Europea y el Tribunal General de la Unión Europea. También incluye decisiones del Tribunal Europeo de Derechos Humanos, el Tribunal de Justicia de la Asociación Europea de Libre Comercio (EFTA) y en esta ocasión también del Comité Europeo de Derechos Sociales. Si usted desea realizar comentarios, los puede enviar a jean.jacqmain@ulb.ac.be.

** De la Parte I "igualdad de género", ha traducido los epígrafes 5 "protección de la maternidad”, 6 "permiso parental”, y "apéndice: el acceso a bienes y servicios"; y ha realizado una revisión general con Jean Jacqmain, autor del estudio.

*** De la Parte I "igualdad de género", ha traducido el apartado de "legislación" y los epígrafes 1 "igualdad retributiva", 2 "igualdad en los regímenes profesionales de seguridad social”, 3 "igualdad en las condiciones de trabajo", y 4 "igualdad en los regímenes legales de seguridad social"

${ }_{* * * *}^{*}$ De la Parte II "otras discriminaciones", ha traducido el apartado "legislación” y los epígrafes 1 "discriminación por razón de raza y del origen étnico", y 2 "discriminación por razón de edad”.

***** De la Parte II "otras discriminaciones", ha traducido los epígrafes 3 "discriminación por razón de la discapacidad", 4 “discriminación por razón de la orientación sexual”, y 5 “discriminación más allá del marco general”. 
Resumen. El estudio aborda el análisis de las sentencias dictadas en aplicación del principio de igualdad de trato y oportunidades desde el 1 de septiembre de 2019 hasta el 31 de agosto de 2020 por el Tribunal de Justicia y el Tribunal General de la Unión Europea. También incluye sentencias y decisiones dictadas en ese periodo por el Tribunal Europeo de Derechos Humanos, el Tribunal de Justicia de la Asociación Europea de Libre Comercio (EFTA) y el Comité Europeo de Derechos Sociales.

Palabras clave: Tribunal de Justicia de la Unión Europea, Tribunal Europeo de Derechos Humanos, Principio de igualdad de trato y de oportunidades.

Abstract. This paper deals with the analysis of judgments related to the principle of equal treatment and opportunities and delivered from September 1, 2019 until August 31, 2020 by the Court of Justice and General Court of the European Union. It also includes judgments and decisions on the subject during this period issued by the European Court of Human Rights, the Court of Justice of European Free Trade Association (EFTA) and the European Committee of Social Rights.

Keywords: Court of Justice of the European, European Court of Human Rights, Principle of equal treatment and opportunities.

\section{IGUALDAD ENTRE TRABAJADORES MASCULINOS Y FEMENINOS}

Legislación. Sin novedades legislativas.

Jurisprudencia. En cuanto a la jurisprudencia, el Tribunal de Justicia de la Unión Europea vuelve, en un número limitado de asuntos, sobre ciertas cuestiones, algunas incluso ya antiguas. Otras jurisdicciones europeas ofrecen complementos adicionales a la Corte de Luxemburgo; en ocasiones son complementos no esperados.

\section{Igualdad retributiva}

1.1. Auto del Tribunal de Justicia de la Unión Europea de 15 de octubre de 2019, O H y E R, C-439/18 Y C-472/18 acumulados

En general, el trabajo a tiempo parcial se puede realizar de dos maneras: horizontal (todos los días) o vertical (solo en determinados días o períodos). Derivar consecuencias adversas para las personas empleadas en cualquiera de los dos regímenes conduce inevitablemente a reproches de discriminación, que pretende impedir el Acuerdo Marco Europeo de 6 de junio de 1997 (Directiva 97/81/CE). Así, en un caso que atañía a la tripulación de cabina de la aviación civil italiana, el Tribunal de Justicia ${ }^{1}$, sin implicar la dimensión de género, había decidido que una diferencia de trato no estaba justificada. Se trataba en ese caso del cálculo de la remuneración utilizada como base para la pensión de jubilación; de ahí que el Tribunal de Justicia tuviera ciertas dificultades para demostrar su naturaleza profesional y que guardaba relación con el Acuerdo Marco.

\footnotetext{
${ }^{1}$ Sentencia del TJUE de 10 de junio de 2010, Bruno y Pettini, C-395/08 y C-396/08, asuntos acumulados.
} 
Más recientemente, un Juzgado de lo Social de Barcelona ha obtenido sucesivamente del Tribunal de Justicia la constatación de discriminación indirecta contra la mujer, primero en el ámbito de la pensión de jubilación ${ }^{2}$, y después en el del desempleo ${ }^{3}$; estas prestaciones que eran incuestionablemente legales escapaban del Acuerdo Marco, pero sí están previstas en la Directiva 79/7/CEE, regímenes legales de Seguridad Social.

A su vez, el Tribunal Superior de Justicia de Galicia se ha dirigido al Tribunal de Justicia en relación con dos trabajadoras que son personal laboral de la Agencia Tributaria: en el asunto de que se trata, la cuestión es el cálculo de la antigüedad en el servicio que da derecho a trienio, como complemento de la remuneración; así definido, el objeto del litigio permite combinar el Acuerdo Marco con la Directiva 2006/54/CE.

En el supuesto de hecho se trata de un tiempo parcial vertical, y a este régimen es al que el convenio colectivo aplicable le vincula el cálculo de la antigüedad según los servicios realmente prestados, y no según la duración de la relación laboral como sucede en el supuesto del personal a tiempo completo. Así pues, una aplicación tan mecánica del principio pro rata temporis conduce a una doble penalización, puesto que la remuneración ya es proporcional a las prestaciones de servicios, como lo ha observado el Tribunal en Espadas Recio; es más, la cláusula 4.2 del Acuerdo Marco solo recomienda la aplicación de principio pro rata cuando resulta apropiado.

De la misma manera que los jueces catalanes, los gallegos han recopilado cuidadosamente las estadísticas ${ }^{4}$ que prueban la presencia mayoritaria de mujeres en la categoría del trabajo a tiempo parcial vertical en la Agencia Tributaria. El Tribunal de Justicia solo ha necesitado un Auto para fallar que la cláusula 4 del Acuerdo Marco y el artículo 14.1 de la Directiva 2006/54/CE se oponen a las disposiciones cuestionadas ${ }^{5}$.

Véase, además, infra, la Sentencia Schuch-Ghannadan.

\subsection{Decisiones del Comité Europeo de Derechos Sociales de 6 de diciembre de 2019, Reclama-} ciones $n^{\circ}$ 124/2016 a 138/2016, University Women of Europe vs. Noruega e.a. ${ }^{6}$

Ante el Comité Europeo de Derechos Sociales, la organización University Women of Europe presentó reclamaciones colectivas contra catorce Estados Miembros de la Unión Europea y contra Noruega, invocando, en lo relativo a la igualdad de género, diversas violaciones de la Carta Social Europea revisada. Con la excepción de Suecia, el Comité ha con-

\footnotetext{
${ }^{2}$ Sentencia del TJUE de 22 de noviembre de 2012, Elbal Moreno, C-385/11; Jean Jacqmain "Crónica de la jurisprudencia europea sobre igualdad de género (de 1/9/2012 a 31/8/2013)", publicada en Aequalitas: Revista jurídica de igualdad de oportunidades entre mujeres y hombres, número 33, 2013, p. 9. Véase también la Sentencia del TJUE de 8 de mayo de 2019, Villar Láiz, C-161/18; Jean Jacqmain, "Crónica de la jurisprudencia europea sobre igualdad (De 1/9/2018 a 31/8/2019)", Femeris, Vol. 5, no 2, pp. 242-243.

${ }^{3}$ Sentencia del TJUE de 9 de noviembre de 2017, Espadas Recio, C-98/15; Jean Jacqmain, “Crónica de la jurisprudencia europea sobre igualdad (De 1/9/2017 a 31/8/2018)", Femeris, Vol. 4, no 2, pp. 195-196.

${ }^{4}$ Gracias al sentido escrupuloso de la publicidad del servicio público del que da ejemplo la Agencia Tributaria concernida en el caso, que ofrece en su sitio web los datos cuantitativos relativo a su personal.

${ }^{5}$ En consecuencia, el TJUE ha podido aplicar la radiación de la doctrina a dos asuntos similares, también provenientes del TSJ de Galicia: S J, C-705/18, y R K, C-85/19 (Autos de 17 de septiembre de 2019).

${ }^{6}$ Publicadas las 16 Decisiones el 29 de junio de 2020 (accesibles en www.hudoc.esc.coe.int).
} 
cluido que cada Estado incumplía una o varias disposiciones de la Carta, principalmente los artículos 4.3 (derecho a una igual remuneración entre hombres y mujeres, remuneración igual para trabajo de igual valor) y 20.c) (igualdad de género: remuneración). En particular, las recomendaciones del Comité se refieren a menudo a la ausencia de transparencia salarial, lo que daría peso a la Recomendación 2014/124/UE de 7 de marzo de $2014^{7}$, que la Comisión Europea ha consagrado a esta cuestión.

\section{Igualdad en los regímenes profesionales de seguridad social}

2.1. Sentencia del tribunal de justicia de la unión europea de 7 de octubre de 2019, safeway ltd, $c-171 / 18$

Hace ya 30 años, el Tribunal de Luxemburgo, en el asunto Barber ${ }^{8}$, establecía que las prestaciones generadas en virtud de un régimen profesional de jubilación (incluso las del sistema británico contractualizado que sustituye al régimen legal) se incluían en la noción de remuneración (artículo 119 CEE, después 141 CE, hoy 157 TFUE); de modo que la edad de acceso a la pensión profesional de jubilación no podía ser diferente por razón de sexo, incluso si estaba así dispuesto en el régimen legal. Cediendo a las presiones de las compañías aseguradoras y fondos de pensión, el TJUE había aceptado, sin embargo, limitar en el tiempo el alcance de la sentencia. Una avalancha de procesos y cuestiones prejudiciales lo obligaron enseguida a precisar su análisis ${ }^{9}$, pero la controversia se fue calmando poco a poco, de suerte que, salvo omisión, no se ha vuelto a ver citada la doctrina Barber ante el Tribual de Justicia en los últimos dieciséis años ${ }^{10}$.

Habrá que creer que todavía falta un elemento. Como consecuencia de Barber, la empresa Safeway había anunciado desde 1991 a todas las personas beneficiarias de su régimen de pensión que iba a hacer efectivo el principio de igualdad entre hombres y mujeres, para lo que fijaba los 65 años como la edad uniforme de acceso a la prestación. El Derecho de la Unión no se opone en principio ${ }^{11}$ a una igualación hacia abajo. No obstante, esta intención no se concretó sino hasta 1996, mediante una modificación del Reglamento de pensión trust cuyos efectos se retrotraían hasta 1991, como autoriza la legislación nacional. De ahí que se produjo un litigio referido al periodo 1991-1996, y la Corte de apelación inglesa planteó una consulta al TJUE.

Como propone el Abogado General E. Tanchev, el Tribunal de Luxemburgo recuerda su jurisprudencia constante ${ }^{12}$ según la cual, durante el periodo de tiempo en que una

\footnotetext{
${ }^{7}$ Recomendación 2014/124/UE de 7 de marzo de 2014 sobre el refuerzo del principio de igualdad de retribución entre hombres y mujeres a través de la transparencia, DOCE, L 69, de 8 de marzo de 2014.

${ }^{8}$ Sentencia del TJUE de 17 de mayo de 1990, Barber C-262/88.

${ }^{9}$ STJUE 6/10/1993, Ten Oever, C-109/91; STJUE 14/10/1993, Moroni, C-110/91; STJUE 9/11/1993, Birds Eye Walls Ltd, C-132/91; STJUE 22/12/1993, Neath, C-152/91; STJUE 28/9/1994, Coloroll, C-200/91; STJUE de 28/9/1994, Avdel Systems, C-408/92; STJUE de 28/9/1994, Van dem Akker, C-28/93; STJUE de 28/9/1994, Vroege, C-57/93; STJUE de 28/9/1994, Caso Fisscher, C-128/93.

${ }^{10}$ Sentencia de 9 de diciembre de 2004, Hlozek, C-19/02.

${ }^{11}$ Así, la Sentencia del TJUE (citada) de 28 de septiembre de 1994, Coloroll, asunto C-200/91.

${ }^{12}$ Así, la Sentencia del TJUE (citada) de 28 de septiembre de 1994, Avdel Systems, C-408/92.
} 
discriminación no es eliminada, el grupo desfavorecido debe disfrutar del tratamiento de grupo favorecido (igualación hacia arriba; aquí, acceso a los 60 años como las mujeres). El artículo 119 CEE (aplicable en la época de los hechos) se opone a una medida de igualación inversa con efecto retroactivo a ese periodo de tiempo; incluso si la legislación nacional lo autoriza. Como es una discriminación directa basada en el sexo, hay que inquietarse al constatar el inciso "en ausencia de una justificación objetiva" que el Tribunal explicita (Punto 43) invocando un imperativo de interés general que consistiría en el equilibrio financiero del régimen de pensión puesto en cuestión, y citando una doctrina jurisprudencial relativa a la libre circulación de trabajadores ${ }^{13}$.

\subsection{Sentencia del Tribunal de Justicia de la Unión Europea de 5 noviembre de 2019, Comisión c. Polonia, C-192/18.}

El año pasado, el Tribunal de Justicia había declarado ${ }^{14}$ fundada la acción por incumplimiento interpuesta por la Comisión contra Polonia. La bajada de la edad legal de jubilación para los magistrados de la Corte Suprema polaca, acompañada de la posibilidad de derogación dejada al uso discrecional por el Jefe del Estado, se había juzgado contraria al artículo 19.1 del TFUE, en cuanto este sistema resulta ser atentatorio contra la inamovilidad de los jueces y la independencia de la magistratura.

Esta primera medida solo afectaba a los miembros de la Corte Suprema. Una ley similar, referida al conjunto de las jurisdicciones y órganos vinculados y atribuyendo la autorización de excepciones al Ministro de Justicia, ha sido objeto de un nuevo recurso de la Comisión, que se resuelve con la misma motivación en la Sentencia, que ahora se comenta, de 5 de noviembre de $2019^{15}$. Como en el anterior caso, la retirada in extremis de la legislación denunciada no ha impedido el pronunciamiento del tribunal, a la vista de la importancia del incumplimiento respecto de los principios del Estado de Derecho.

Además, en este segundo recurso de incumplimiento, la Comisión había presentado otra queja (que es la que ahora nos interesa): la edad uniforme de 67 años se había bajado a 65 años para los hombres y a los 60 años para las mujeres. Dado que el Gobierno polaco sostenía que el régimen cuestionado era legal y se inscribía en la Directiva 79/7/CEE, el Tribunal se remite a su jurisprudencia constante ${ }^{16}$ para establecer que era profesional; de ahí que la discriminación de género, prohibida por el artículo 157 TFUE y la Directiva 2006/54/CE, es manifiesta. El Gobierno polaco intentó justificar la diferencia como una acción positiva para las mujeres -que ni siquiera autoriza la Directiva 79/7/CEE que invoca ${ }^{17}$. El Tribunal,

\footnotetext{
${ }^{13}$ Así la Sentencia del TJUE de 7 de marzo de 2018, D W, C-651/16; Jean Jacqmain, "Crónica de la jurisprudencia europea sobre igualdad (De 1/9/2017 a 31/8/2018)", Femeris, Vol. 4, no 2, p. 201.

${ }^{14}$ Sentencia del TJUE de 24 de junio 2019, Comisión c. Polonia, C-619/18; Jean Jacqmain, “Crónica de la jurisprudencia europea sobre igualdad (De 1/9/2018 a 31/8/2019)”, Femeris, Vol. 5, no 2, pp. 253-254.

${ }^{15}$ Esta decisión y la precedente han encontrado su proyección en otra Sentencia de 19 de noviembre 2019, A Ket alii, C-585/18, C-624/18 y C-625/18, referidas a cuestiones prejudiciales acumuladas.

${ }^{16}$ Desde la Sentencia del TJUE de 28 de noviembre de 1994, Beune, C-7/93.

${ }^{17}$ Véase la Sentencia del TJUE de 21 de noviembre 1990, Integrity, C-373/89.
} 
siguiendo al Abogado General E. Tanchev, refuta el argumento: la acción positiva pretende ayudar a las mujeres a compensar las desventajas que suben en sus carreras profesionales, pero no pretende que estas terminen más rápidamente ${ }^{18}$.

\section{Igualdad en las condiciones de trabajo}

3.1. Sentencia del Tribunal de Justicia de la Unión Europea de 3 de octubre de 2019, SchuchGhannadan, C-274/18.

Las prácticas de empleo del personal científico en las universidades austriacas han dado lugar a un litigio en forma de partida de billar entre tres directivas de la Unión europea.

De conformidad con el principio, inscrito en el Acuerdo Marco sobre contratos de duración determinada (Directiva 1999/70/CE), según el cual esta modalidad de contratación deber permanecer tan limitada como sea posible, la legislación nacional sobre universidades fija en seis años el periodo máximo durante el que se pueden suceder contratos de duración determinada, o de ocho años en caso de prestaciones a tiempo parcial. Cuando medie una justificación objetiva ligada a la naturaleza del contrato, el límite temporal se puede extender a diez años, o doce en caso de tiempo parcial.

Habiendo estado empleada durante un total de once años por la Facultad de Medicina de Viena, hasta la expiración de su ultimo contrato, una investigadora sostiene que si hubiera estado contratada a tiempo completo su contrato se habría convertido en indefinido (por sobrepasar el máximo de 10 años), y que el periodo suplementario de dos años admitido por la ley resulta, respecto de los trabajadores a tiempo parcial, en una discriminación contraria al Acuerdo Marco en esta materia (Directiva 97/81/CE).

Mas allá aún, afirma que la discriminación directa así enunciada se refuerza con otra, una indirecta, respecto de las mujeres, contraviniendo la Directiva 2006/54/CE.

En el centro de este litigio complejo, el Arbeits und Sozialgericht (Tribunal Laboral y Social) de Viena somete estas dos cuestiones al Tribunal de Justicia de Luxemburgo.

Aunque el Abogado General G. Pitruzzella consideraba que era preciso, en primer lugar, confrontar la legislación austriaca cuestionada con la Directiva 1999/70/CE, el Tribunal de Justicia constata que las cuestiones prejudiciales no la citan, y que, por lo tanto, no se ha de examinar tal instrumento normativo al resolver la cuestión prejudicial.

En cuanto a la Directiva 97/81/CE, el Tribunal de Justicia declara que la cláusula 4.1 del Acuerdo Marco se opone al régimen de duración suplementaria autorizada por la legislación austriaca a menos que haya justificaciones objetivas que admite esa cláusula y que corresponde a la jurisdicción nacional verificar. En particular, siguiendo al Abogado General, el apartado 2 que consagra el principio pro rata temporis "cuando sea

\footnotetext{
${ }^{18}$ El tribunal había presentado la misma refutación en la Sentencia de 17 de julio de 2014, M. y B. Leone, C-173/13; Jean Jacqmain “Crónica de la jurisprudencia europea sobre igualdad de género (de 1/9/2013 a 31/8/2014)", publicada en Aequalitas: Revista jurídica de igualdad de oportunidades entre mujeres y hombres, número 35, 2014, pp. 17-18.
} 
apropiado"19 no se aplica puesto que los suplementos de duración no son proporcionales a los periodos de prestación de servicios. Durante el procedimiento, el Gobierno austriaco no ha hecho valer más que el argumento de que la experiencia se adquiere de modo menos rápido a tiempo parcial que a tiempo completo; esto resulta totalmente incongruente respecto de una investigadora que ha prestado servicios durante once años; y también se debe recordar que el Tribunal ya había refutado este argumento en los asuntos referidos a la contratación por los servicios públicos alemanes ${ }^{20}$.

Por último, el Tribunal de Justicia admite la eventualidad de una discriminación indirecta de género, contraria al artículo 2.1.b) de la Directiva 2000/54/CE, con los requisitos habituales de verificación de las justificaciones que sometiera el gobierno. Una vez más, el Tribunal deja pasar la ocasión de conciliarse con la definición de discriminación indirecta por razón de sexo actualmente inscrita en la Directiva ("desventaja particular respecto de las personas de un sexo, en relación con las del otro"), insistiendo en la cuestión del impacto adverso constatado estadísticamente, lo que en el caso le viene dado pues las cuestiones prejudiciales ya alegaban la disparidad en el número de trabajadores y trabajadoras afectados por el trabajo a tiempo parcial.

Sin embargo, sí hay que alegrase de una concesión inesperada del Tribunal de Justicia de la Unión Europea en la interpretación del artículo 19.1 de la Directiva, que es la norma relativa a la carga de la prueba: la parte que se considera víctima de una discriminación indirecta y que tiene la carga de presentar dicha apariencia, no tiene la obligación de presentar ni hechos ni datos estadísticos a los que le resulta difícil o imposible acceder. Tal indulgencia solo ha precisado 26 años para manifestarse ${ }^{21}$.

Véase, además, infra, el Auto $O H$ y $E R$.

\section{Igualdad en los regímenes legales de seguridad social}

\subsection{Sentencia del Tribunal de Justicia de la Unión Europea de 12 de diciembre de 2019, $W A^{22}$, C-450/18.}

Cabe recordar sin mucho esfuerzo que las ventajas de pensión reservadas a las mujeres acechan desde hace veinte $a_{n}{ }^{23}$ al régimen francés de jubilación del funcionariado, analizado por la Corte de Luxemburgo como profesional e integrado en el concepto de retribución (artículo 157 TFUE). En términos bastantes similares, pero en materia de un régimen legal de pensión, se ha sometido de nuevo la cuestión al Tribunal de Justicia.

\footnotetext{
${ }^{19}$ Para una exploración magistral de esta noción, véanse las conclusiones de la Abogada General E. Sharpston referidas a la Sentencia de 5 de noviembre de 2014, Österreichischer Gewerkschaftsbund, C-476/12; Jean Jacqmain "Crónica de la jurisprudencia europea sobre igualdad de género (de 1/9/2014 a 31/8/2015)", publicada en Aequalitas: Revista jurídica de igualdad de oportunidades entre mujeres y hombres, número 37, 2015, pp. 17-18.

${ }^{20}$ Sentencias del TJUE de 2 octubre de 1997, Gerster, C-1/95, y Kording, C-100/95.

${ }^{21}$ Compárese con la Sentencia de 30 de noviembre 1993, Kirsammer-Hack, C-189/91.

${ }^{22}$ Por razones de anonimización, el Tribunal de Justicia de la Unión Europea atribuye a las personas físicas iniciales elegidas aleatoriamente, lo que explica la aparición de letras que no son usualmente empleadas en el país concernido; como aquí la $\mathrm{W}$ (salvo que se trate de un nombre extranjero).

${ }^{23}$ La ultima peripecia fue la Sentencia M. y B. Leone, citada supra, nota 18.
} 
En España, la Ley General de la Seguridad Social concede un suplemento de prestación (de jubilación, muerte y supervivencia o incapacidad permanente) a las mujeres que han tenido al menos dos hijos biológicos o adoptados. Con derecho a pensión de incapacidad, un trabajador varón que reunía esos requisitos solicita el complemento, y el organismo competente rechaza la solicitud. Presenta demanda ante el Juzgado de lo Social 3 de Girona y después muere. Su viuda continua el procedimiento, cuyo objeto se limita al valor del complemento discutido hasta la fecha del fallecimiento. El Juzgado interroga a la Corte sobre la adecuación de la norma española al derecho de la Unión.

Ayudado por el análisis minucioso del Abogado General M. Bobek, el tribunal establece en primer lugar, que, contrariamente a la formulación de la cuestión prejudicial, el litigio no cabe inscribirlo en el artículo 157 TFUE ni en la Directiva 2006/54/CE, sino en la 79/7/CEE, cuyo artículo 4.1 prohíbe la discriminación de género en los regímenes legales de pensión. El Gobierno español alega la excepción inscrita en el apartado 2, que se refiere a "la protección de la mujer por razón de su maternidad". Sin embargo, la disposición nacional contestada exige que la trabajadora beneficiaria haya tenido al menos dos hijos (eventualmente adoptados) sin establecer ninguna relación con las pruebas físicas y profesionales que implica la maternidad; y la justificación proporcionada por la Ley General de la Seguridad Social, "respecto a su contribución demográfica a la seguridad social" se aplicaría también a un padre.

Por su parte, el artículo 7.1.b) de la Directiva autoriza a los estados miembros a excluir del campo de transposición "las ventajas acordadas en materia del seguro de vejez a las personas que han criado hijos". Esta facultad no había sido evocada ante el Tribunal que anteriormente la había aplicado con unos límites estrechos ${ }^{24}$, pero, en el supuesto del litigio, basta observar que la disposición española no requiere que la persona los haya criado, sino solamente que los haya tenido. La Directiva 79/7/CEE se opone entonces a una disposición interna constitutiva de una discriminación directa contra los hombres ${ }^{25}$.

\section{Protección de la maternidad}

5.1. Sentencia del Tribunal de Justicia de la Unión Europea de 19 de septiembre de 2019, Dakneviciute, $C-544 / 18$

Hace seis años (STJUE de 19/06/2014, Saint Prix, C-507/12), el Tribunal de Justicia había respondido al Tribunal Supremo del Reino Unido que a los ojos del artículo 45 del

\footnotetext{
${ }^{24}$ Sentencia del TJUE de 11 de abril de 2013, Soukupová, C-401/11; comentada por Jean Jacqmain "Crónica de la jurisprudencia europea sobre igualdad de género (de 1/9/2012 a 31/8/2013)", publicada en Aequalitas: Revista jurídica de igualdad de oportunidades entre mujeres y hombres, número 33, 2013, pp. 9-10. Sobre esta temática, véase también la Sentencia de 17 de febrero de 2011 del Tribunal Europeo de Derechos Humanos, Andrle v. República Checa, Appl. no 6268/08; comentada por Jean Jacqmain, “Crónica de la jurisprudencia europea sobre igualdad de género (de 1/9/2010 a 31/8/2011)", Aequalitas: Revista jurídica de igualdad de oportunidades entre mujeres y hombres, número 29, 2011, pp. 8-9.

${ }^{25}$ En consecuencia, el Tribunal de Justicia ha podido proyectar la doctrina de dos asuntos similares en el Auto de 4 de febrero de 2020, K A, C-811/18, y en el Auto de 5 de marzo de 2020, L J, C-861/19.
} 
TFUE (libre circulación de trabajadores asalariados), una francesa empleada en el Reino Unido que había interrumpido su actividad durante los últimos meses de un embarazo difícil y los primeros seguidos al nacimiento, no perdía la calidad de trabajadora asalariada en el sentido de la Directiva 2004/38/CE (libre circulación de ciudadanos de la Unión). Por ello, la trabajadora tenía derecho a una prestación de seguridad social destinada a cubrir tales situaciones. Nos habíamos cuestionado entonces si es que no éramos demasiado ingenuos por sorprendernos de que aún pudiera resultar necesario dar respuesta a una tan elemental cuestión prejudicial ${ }^{26}$.

La respuesta a nuestra cuestión es que sí que éramos demasiado ingenuos pues el Upper Tribunal (Cámara de apelaciones de la Administración del Reino Unido) ha sometido recientemente a la Corte de Justicia un caso muy similar, aunque es verdad que con algunos elementos de hecho diferenciales. Una lituana que trabajaba por la noche como asalariada abandona su empleo porque está embarazada y se instala como esteticién autónoma. Después del permiso de maternidad durante el cual recibió la prestación de seguridad social ad hoc, la trabajadora intenta retomar su actividad autónoma, pero, al constatar que le proporcionaba pocos ingresos, la abandona, y finalmente retorna a un empleo asalariado. Mientras tanto, había solicitado una prestación por hijo a cargo, que le es denegada.

Con referencia a su asunto previo (STJUE de 19/06/2014, Saint Prix, C-507/12), el Tribunal de Justicia ofrece una respuesta idéntica, aunque esta vez interpreta el artículo 49 TFUE (libre circulación de trabajadores autónomos) y cita el considerando 18 del preámbulo de la Directiva 2010/41/UE, relativa a la igualdad de género en el trabajo por cuenta propia, en el cual se subraya la vulnerabilidad económica y física que entraña el embarazo.

\subsection{Sentencia del Tribunal de Justicia de la Unión Europea de 7 de noviembre de 2019, W N contra Parlamento, T-431/18}

El despido de la asistente parlamentaria acreditada de un parlamentario europeo ha desembocado en un litigio ante el Tribunal de Justicia de la Unión Europea que, en un aspecto esencial, aparenta poco convincente. En virtud del RAA (que es el Régimen Aplicable a otros Agentes de la Unión europea que aquellos que caen dentro del Estatuto de la Función Pública), el parlamentario había solicitado el despido en razón de una ruptura de confianza debido a varias faltas profesionales. La autoridad que, en nombre del parlamento, realiza las contrataciones, había solo verificado que el motivo justificaba la ruptura del contrato. El Tribunal de Justicia considera que los alegatos de la demandante carecen de fundamento.

No obstante, la interesada había solicitado la aplicación del procedimiento previo de conciliación previsto por el RAA y comunicado su embarazo a la conciliadora, la cual había creído necesario mencionarlo en la reunión. Así fue como el parlamentario recibió la in-

\footnotetext{
${ }^{26}$ Comentario de la STJUE de 19 de junio de 2014, Saint Prix, C-507/12, en Jean Jacqmain "Crónica de la jurisprudencia europea sobre igualdad de género (de 1/9/2013 a 31/8/2014)”, publicada en Aequalitas: Revista jurídica de igualdad de oportunidades entre mujeres y hombres, número 35, 2014, p. 21.
} 
formación sobre esta circunstancia, y la forma en que reaccionó ante ella varió mucho de una versión a otra. Según la demandante, el parlamentario habría dicho que el embarazo "violó sus derechos fundamentales" (de él). El Parlamento, partido de oposición, se refirió al acta de la reunión, en la que señaló que el parlamentario estaba "muy sorprendido" ( de qué?); pero, por otro lado, no se discute que este tuvo una "reacción negativa" y realizó "comentarios inapropiados".

En esencia, la demandante extrae de esta peripecia un motivo relacionado con la discriminación de género. La base para esto (artículos 21 y 23 de la Carta de los Derechos Fundamentales de la Unión, la Directiva 2006/54/CE, la suficiencia de las disposiciones del RAA) no es tema de largos debates. Pero el Tribunal cita un precedente reciente ${ }^{27}$ al afirmar que "el mero embarazo de un agente" (énfasis nuestro: ¿en serio?) no permite la presunción de discriminación; se deben aportar más pruebas. Dado que el parlamentario desconocía el embarazo cuando realizó su solicitud, las razones que ofreció en apoyo de la misma no guardan relación alguna con el embarazo.

He aquí la debilidad principal de la sentencia. Según el RAA, es la autoridad competente quien decide el despido avalando los motivos presentados por el parlamentario. Sin embargo, durante la reunión de conciliación, ¿añadió o no un motivo, consistente en el embarazo, a los que había planteado en su solicitud? Esta cuestión hubiera debido ser estudiada mucho más de cerca por el Tribunal.

\section{Permiso parental}

6.1. Sentencia del Tribunal de Justicia de la Unión Europea de 18 septiembre de 2019, Ortiz Mesonero, C-366/18

Empleado en una empresa y casado con una abogada, un trabajador español desea una adaptación de su régimen de trabajo a fin de ocuparse de sus dos hijos pequeños. El Estatuto de los Trabajadores confiere, por tal motivo, el derecho a una reducción de la jornada de trabajo acompañado de una disminución proporcional de la remuneración, pero en este caso si el empleador accedía a sacar al trabajador del régimen de tres turnos alternos y asignarlo al único turno de mañana, ni se produciría reducción de la jornada laboral ni reducción de la retribución. El empleador se negó y surgió una disputa ante un Juzgado de lo Social de Madrid. Observando que casi el 24\% de las trabajadoras y solo el 2\% de los trabajadores reducen su tiempo de trabajo debido a sus responsabilidades familiares, el Juzgado invitó al Tribunal de Justicia a aclarar el impacto de la Directiva 2006/54/CE, pero también la 2010/18/UE relativa al permiso parental.

El Tribunal de Justicia responde rápidamente que, si la situación litigiosa resultaba una discriminación indirecta contra las mujeres, no se veía qué desventaja particular su-

\footnotetext{
${ }^{27}$ Sentencia del TJUE de 26/10/2017, HB vs. Comisión, T-706-IGP; véase Jean Jacqmain, “Crónica de la jurisprudencia europea sobre igualdad (De 1/9/2018 a 31/8/2019)", Femeris, Vol. 5, no 2, p. 200.
} 
friría un trabajador masculino. Se evita así profundizar el estudio de una curiosa paradoja (una persona que pertenece a la categoría favorecida es tratado como las que se integran en la perjudicada) y el Tribunal parece que no quiere volver a sus sugerentes consideraciones sobre la discriminación indirecta emitidas en CHEZ (STJUE de 16 de julio de 2015, C-83/14).

Además, la modalidad controvertida de régimen del tiempo de trabajo no se corresponde con ninguna de las previsiones del acuerdo marco revisado sobre el permiso parental y, por tanto, no parece aplicable la Directiva 2010/18/UE. Por tanto, el Tribunal de Justicia concluye que el objeto del litigio es ajeno a dicha Directiva. En consecuencia, no se debe interpretar el artículo 33, apartado 2 (derecho al permiso parental) de la Carta de los Derechos Fundamentales de la Unión, como tampoco (por lo que se dijo arriba) su artículo 23 , relativo a la igualdad de género.

Observamos una vez más ${ }^{28}$, que la jurisdicción nacional no parece hacer referencia al caso juzgado por el Tribunal Europeo de Derechos Humanos ${ }^{29}$ sobre la misma disposición del ET.

6.2. Sentencia de 19 diciembre 2019 del Tribunal de Justicia de la Asociación Europea de Libre Comercio, Autoridad de Supervisión contra Noruega, E-1/18

Diversas lagunas y ambigüedades de la legislación de la Unión Europea han complicado un litigio sometido al Tribunal de Justicia de la Asociación Europea de Libre Comercio (EFTA).

En Noruega, la legislación de trabajo reconoce, en el caso de nacimiento o adopción, un permiso parental de 12 meses, que incluye el descanso postnatal obligatorio (si ha habido parto): una parte reservada para la madre, otra para el padre (la eventualidad de una pareja de diferente composición no fue planteada en el litigio) y una tercera a utilizar como ellos lo acuerden. Durante esta licencia, la legislación de seguridad social proporciona una asignación parental: la madre tiene derecho a ella incondicionalmente, mientras que se concede al padre solo si la madre reanuda una actividad o formación profesional o no puede trabajar.

Esta diferencia de trato llevó a la Autoridad de Supervisión (ESA) a iniciar un procedimiento de infracción; consideró que el subsidio estaba destinado a promover el recurso a la licencia parental, que se enmarca dentro del concepto de condiciones de trabajo, por lo que existía una discriminación directa contra los hombres, prohibida por el artículo 14.1 c) de la Directiva 2006/54/CE. Cuando se le consultó, la Comisión Europea compartió el análisis de la ESA.

\footnotetext{
${ }^{28}$ STJUE de 16 de junio de 2016, Rodríguez Sánchez, C-351/14; véase Jean Jacqmain “Crónica de la jurisprudencia europea sobre igualdad de género (de 1/9/2015 a 31/8/2016)”, publicada en Aequalitas: Revista jurídica de igualdad de oportunidades entre mujeres y hombres, número 39, 2016, p. 10-11.

${ }^{29}$ STEDH de 19 de febrero de 2013, García Mateos vs. España, demanda no 38285/09; véase Jean Jacqmain “Crónica de la jurisprudencia europea sobre igualdad de género (de 1/9/2012 a 31/8/2013)", publicada en Aequalitas: Revista jurídica de igualdad de oportunidades entre mujeres y hombres, número 33, 2013, pp. 10-11.

${ }^{30}$ Accesible en www.eftacourt.int.
} 
La primera referencia que viene a la mente es el caso Maïstrellis ${ }^{31}$, relativo al permiso parental de los magistrados griegos, en el cual el Tribunal de Justicia de la Unión Europea había reconocido una discriminación directa porque solo el ejercicio de una actividad profesional por la madre le daba al padre derecho al permiso. El Tribunal EFTA observa, sin embargo, que el Acuerdo marco revisado que es objeto de la Directiva 2010/18/UE no impone la concesión de una prestación social (y tampoco la nueva Directiva 2019/1158/ UE, añadimos), por lo que una sentencia que se refiera al derecho al permiso parental carece de pertinencia en el presente caso.

Por tanto, el debate ante el Tribunal se centra en la posibilidad de equiparar la asignación parental noruega con la remuneración a los ojos de la Directiva 2006/54/CE. El antiguo caso Jackson y Cresswell ${ }^{32}$ no sirve: con respecto a una prestación de asistencia social británica (como tal, excluida del ámbito de aplicación de la Directiva 79/7/CEE) destinada a complementar los recursos inadecuados, el Tribunal de Justicia había dictaminado que, si esta ventaja podía favorecer la integración profesional de las familias monoparentales (principalmente mujeres), esta consideración no era suficiente para someterla, como condición laboral, a la entonces vigente Directiva 76/207/CEE. Por contra, en Meyers ${ }^{33}$, el Tribunal de Justicia tuvo que examinar el crédito familiar, otro sistema legal de seguridad social británico (también excluido del ámbito de aplicación de la Directiva 79/7/CEE, que no cubre las prestaciones familiares); con el objetivo de inducir a los trabajadores con salarios bajos a permanecer en la fuerza laboral, el beneficio solo estaba dirigido a las parejas. La diferencia de trato hacia las familias monoparentales era obvia y el Tribunal había aceptado la alegación de la Directiva 76/207/CEE para establecer la discriminación indirecta contra la mujer. La ESA se basaba en esta sentencia.

No obstante, el Tribunal de Justicia de la EFTA acepta el argumento del Gobierno noruego de que el subsidio parental depende de los recursos de la persona interesada, que no consisten solo en su remuneración como empleado/a, sino que también puede provenir de una actividad autónoma, o de prestaciones de la seguridad social, por ejemplo. En consecuencia, no es posible la aplicación de la Directiva 2006/54/CE y el Tribunal rechaza la solicitud de la ESA.

Sin duda, la posición del Tribunal parece formalista, y de hecho contraria a los objetivos de conciliación de la actividad profesional y las responsabilidades familiares, que perseguirá la Directiva 2019/1158 /UE y que, además, la legislación noruega pone en vigor de manera ejemplar. Sin embargo, la sentencia ilustra que la timidez del nuevo instrumento relativo a la compensación del permiso parental no augura nada bueno para su aplicación en los Estados miembros. Además, el carácter incompleto de la Directiva 79/7/ CEE, más de cuarenta años después de su adopción, sigue siendo un serio obstáculo para el logro de la igualdad de género.

${ }^{31}$ STJUE de 16 de julio de 2015, Maïstrellis, C-222/14, Jean Jacqmain "Crónica de la jurisprudencia europea sobre igualdad de género (de 1/9/2014 a 31/8/2015)”, publicada en Aequalitas: Revista jurídica de igualdad de oportunidades entre mujeres y hombres, número 37, 2015, p. 21.

${ }^{32}$ STJUE de 16 de julio de 1992, C-63/91 y C-64/91 acumulados.

${ }^{33}$ STJUE de 13 de julio de 1995, C-116/84. 
6.3. Decisión del Comité Europeo de Derechos Sociales de 11 septiembre de 2019, Central Union for Child Welfare c. Finlandia, reclamación nํo 139/2016

Por simple asociación de ideas debido a la proximidad de ciertos aspectos, debemos mencionar una decisión del Comité Europeo de Derechos Sociales. En Finlandia, la legislación garantizaba a todo niño en edad preescolar el acceso a un centro de atención de la primera infancia, creado por el municipio y subvencionado por el Estado. En 2016, una enmienda legislativa dio a las autoridades locales la opción de limitar a 20 horas por semana si uno de los padres del niño estaba de baja por maternidad, paternidad o permiso parental, o incluso desempleado. Ante una queja colectiva, el Comité, por amplia mayoría, encontró la violación de varias disposiciones de la Carta Social Europea revisada: artículo E (no discriminación) combinado con el 17.1.a) (protección social infantil); artículo 27.1.c) (igualdad de trato para los trabajadores con responsabilidades familiares); artículo E combinado con el 16 (protección social de la familia).

\section{APÉNDICE: EL ACCESO A BIENES Y SERVICIOS}

\section{Sentencia del Tribunal Europeo de Derechos Humanos de 24 de octubre de 2019, J.D. y A.C. v. Reino Unido, demandas n 32949/17 y 34614/17}

El Tribunal Europeo de Derechos Humanos ha tenido que atender dos recursos originados por la legislación de seguridad social del Reino Unido, pero que se refiere a la concesión de asignaciones para vivienda. De las demandantes, una vive con su hija gravemente discapacitada en un apartamento adaptado que tiene tres dormitorios. La otra vive también con su hijo en una casa de tres habitaciones, pues al haber sido víctima y estar aún gravemente amenazada por la violencia extrema de una expareja masculina, se beneficia de un programa de protección policial que incluye una habitación segura. En 2012, una revisión de la legislación redujo el monto de la asignación para cada una al entender el alojamiento sobredimensionado; en consecuencia, el beneficio ya no cubre el monto del alquiler. Las dos mujeres pudieron obtener, con carácter provisional, otro subsidio, este opcional, pero mientras la primera lo sigue recibiendo, la segunda lo mantiene solo por la intervención del ministro competente. Ambas impugnaron la reducción del subsidio de vivienda, sin éxito en todos los niveles, incluido el Tribunal Supremo.

Tratando sus solicitudes desde el ángulo del artículo 1 del Primer Protocolo combinado con el artículo 14 del CEDH, el Tribunal concluye, con respecto a la primera, que la aplicación de la reforma de 2012, que tiene como objetivo una mejor distribución de las viviendas según las necesidades reales, no es excesiva, ya que la solicitante reconoce que podría acondicionarse adecuadamente una vivienda más pequeña; además, la concesión del beneficio opcional compensó la reducción del beneficio. Por lo tanto, no hay violación de las disposiciones citadas.

En relación con la segunda demandante, el Tribunal considera que la reducción de la asignación contraviene la obligación del poder público de permitir a las víctimas de 
violencia doméstica, principalmente mujeres ${ }^{34}$, mantener una vivienda adecuada para garantizar su protección. Se resuelve la existencia de una violación de las disposiciones citadas y se le concede a la demandante 1.000 euros en concepto de daño moral. Los jueces K. Wojtyczek y A. Pejchal, sin embargo, expresan una opinión disidente que cuestiona la discriminación indirecta de género.

¿Podría haber entrado en juego la legislación de la Unión Europea durante los procedimientos nacionales? Sobre el segundo caso, lo más probable; aunque la prestación controvertida está incluida en la seguridad social legal en el Reino Unido, no entra dentro del ámbito de aplicación material de la Directiva 79/7/CEE, sino más bien dentro del ámbito de aplicación material de la Directiva 2004/113/CE, relativa a la igualdad de género en el acceso a bienes y servicios. Por otro lado, en el primer caso, el criterio de discapacidad, considerado como causante de discriminación por asociación ${ }^{35}$, sí se enmarcaría dentro de la Directiva 2000/78/CE, pero esta no se aplica más que en materia de empleo, no en seguridad social legal ni en bienes y servicios.

\section{OTRAS DISCRIMINACIONES}

Legislación. Sin novedades legislativas.

Jurisprudencia. El criterio de la edad centra la mayor parte de la actividad del Tribunal de Luxemburgo; mientras el criterio del origen racial o étnico centra la actividad del Tribunal de Estrasburgo, que también conoce situaciones tan lamentables como sorprendentes.

\section{Discriminación por razón de raza y del origen étnico}

\subsection{Decisión del Tribunal Europeo de Derechos Humanos de 1 de octubre de 2019, Memet} a.o. v. Rumanía, demanda ${ }^{\circ} 16401 / 16$

Una vez más ${ }^{36}$, el Tribunal Europeo ha tenido que conocer de casos relativos a personas gitanas privadas de vivienda. En Rumania, los afectados fueron expulsados, primero realojados en una escuela abandonada, luego en contenedores, y fueron amenazados con un nuevo desalojo por no pagar las facturas de agua y energía. Este caso había experimentado altibajos judiciales que habían producido algunos resultados favorables, otros no; el 30 de marzo de 2016, el propio Tribunal recomendó una medida cautelar (suspensión de la decisión de desalojo), con base en el artículo 39 de su Reglamento.

\footnotetext{
${ }^{34}$ Sobre esta cuestión, K. Nousiainen y C. Chinkin, Legal implications of EU accession to the Istanbul Convention, European Network of Legal Experts in Gender Equality and Non-Discrimination, 2015, www.equalitylaw.eu.

${ }^{35}$ STJUE de 17 de julio de 2008, Coleman, C-303/06.

${ }^{36}$ Véase las Decisiones del TEDH de 20 de octubre de 2018, Aydarov a.o. v. Bulgaria, demanda n 33586/15, y de 4 de junio de 2019, Yuseinova a.o. v. Bulgaria, demanda $n^{\circ}$ 30472/17; sobre estas Decisiones, véase Jean Jacqmain, “Crónica de la jurisprudencia europea sobre igualdad (De 1/9/2018 a 31/8/2019)", Femeris, Vol. 5, no 2, pp. 249-250.
} 
Los demandantes denunciaron violaciones de los artículos 3, 8, 13 y 14 de la CEDH, pero el Tribunal de Estrasburgo determinó que no se agotaron las posibilidades de realizar acciones internas de reparación; por ello la denuncia se declara inadmisible.

A diferencia de un precedente ${ }^{37}$ que se refería al mismo Estado signatario, los hechos de este caso ocurren después de su adhesión a la Unión Europea, a pesar de lo que los recursos de la Directiva 2000/43/CE y su transposición al Derecho nacional no parecen haber sido explotados. Nuestro cuestionamiento, en la crónica del año pasado ${ }^{38}$, acerca de si las autoridades búlgaras habían realizado los esfuerzos necesarios para darle una publicidad adecuada a la Directiva, especialmente con respecto a la comunidad gitana, nos parece, por tanto, también aquí pertinente, en este caso en relación con Rumanía.

\subsection{Sentencia del Tribunal Europeo de Derechos Humanos de 10 de marzo de 2020, Hudorovič a.o. v. Eslovenia, demandas $n^{\circ} 24816 / 14$ y $25140 / 14$}

La anterior observación también se debería aplicar a Eslovenia, miembro de la Unión desde el 1 de mayo de 2004, en atención a los datos de otro caso presentado ante el Tribunal Europeo. Se trataba de dos demandas de personas gitanas que residían en viviendas precarias en dos localidades diferentes. El tema del litigio se centró en el acceso al agua potable y alcantarillado. En ausencia de conexiones a dichas redes, ¿los municipios se esforzaron lo suficiente en instalar cisternas de agua e inodoros químicos?

Después de un largo enfrentamiento entre las partes, el Tribunal admite que los servicios controvertidos pusieron en juego el artículo 8 de la CEDH (vida privada y familiar). Sin embargo, teniendo en cuenta los medios de que disponen las autoridades públicas y las indemnizaciones pagadas a los demandantes, el Tribunal concluye por unanimidad en un caso, y por 5 votos contra 2 en el otro, que no hubo violación del artículo 8. En cuanto al artículo 14, se observa que también están insuficientemente equipadas con agua potable y alcantarillado muchas localidades aisladas sin relación alguna con las comunidades romaníes. En este sentido, es especialmente lamentable que en el marco del contexto internacional no haya sido mencionada la Sentencia del Tribunal de Justicia de la Unión Europea ${ }^{39}$ sobre otro servicio esencial, el suministro de energía eléctrica.

La opinión parcialmente disidente del Magistrado D. Pavli, junto con su colega E. Kūris, considera que, ante una cuestión tan vital como el derecho al agua potable, el Tribunal concedió demasiado pronto su parecer favorable al gobierno en cuestión.

\footnotetext{
${ }^{37}$ Decisión del TEDH de 4 de abril de 2017, Cazacliu a.o. v. Romania, demanda n 63945/09.

${ }^{38}$ Véase Jean Jacqmain, “Crónica de la jurisprudencia europea sobre igualdad (De 1/9/2018 a 31/8/2019)”, Femeris, Vol. 5, no 2, pp. 249-250.

${ }^{39}$ Sentencia del TJUE de 16 de julio de 2015, CHEZ, C-83/14, citado supra en relación con Ortiz Mesonero.
} 
1.3. Sentencia del Tribunal Europeo de Derechos Humanos de 14 de mayo de 2020, Hirtu e.a. v. Francia, demanda $n^{\circ} 24720 / 13$.

Francia fue también objeto de una acción ante el Tribunal de Estrasburgo sin que se hubiera planteado previamente ante los tribunales nacionales el impacto del Derecho de la Unión, ni siquiera la existencia de una discriminación, en una cuestión que afectaba a varios romaníes, nacionales rumanos, expulsados de tierras que ocuparon ilegalmente en La Courneuve (Seine-Saint-Denis). El Tribunal Europeo de Derechos Humanos desestimó la demanda en virtud del artículo 3 de la CEDH (trato inhumano o degradante), pero consideró que las autoridades no habían tenido suficientemente en cuenta las necesidades particulares de un grupo social desfavorecido, lo que resultó en violación del artículo 8. Además, el procedimiento utilizado solo podía ser impugnado ante los tribunales administrativos, que habían dictado sus decisiones demasiado tarde para que pudieran tener efectividad, contrariamente a los requisitos del artículo 13. A cada uno de los demandantes se le concedieron $3.000 €$ en concepto de daños morales.

1.4. Decisión del Comité Europeo de Derechos Humanos de 14 de mayo de 2020, Pto. $n^{\circ}$ 185/2019, Centro Europeo para los Derechos de los Gitanos vs Bélgica

En 2019 en Bélgica, una gran operación policial llevada a cabo contra 19 asentamientos de personas itinerantes había provocado la confiscación de caravanas y el bloqueo de cuentas bancarias, siendo sus propietarios sospechosos de participar en actividades delictivas. El Centro Europeo para los Derechos de los Gitanos presentó una demanda colectiva ante el Comité Europeo de Derechos Sociales denunciando diversas violaciones de la Carta Social Europea revisada y el Comité Europeo la declaró admisible por unanimidad. Como en un anterior caso, Amnistía Internacional contra Italia ${ }^{40}$, informó al gobierno belga de las medidas inmediatas que debían tomarse para preservar los derechos sociales básicos de los afectados, en particular el acceso al agua.

\section{Discriminación por razón de edad}

2.1. Sentencia del Tribunal de Justicia de la Unión Europea de 5 noviembre de 2019, Comisión c. Polonia, C-192/18. Véase supra.

2.2. Sentencia del Tribunal de Justicia de la Unión Europea de 7 de noviembre de 2019, Cafaro, $C-396 / 18$.

Alrededor de este asunto italiano, flota un aroma de espionaje. En 2012, un piloto empleado por una empresa de transporte aéreo civil fue despedido porque había cum-

\footnotetext{
${ }^{40}$ Decisión del Comité Europeo de Derechos Sociales de 4 de julio de 2019, procedimiento ${ }^{\circ}$ 178/2019; véase Jean Jacqmain, “Crónica de la jurisprudencia europea sobre igualdad (De 1/9/2018 a 31/8/2019)”, Femeris, Vol. 5, no 2, pp. $249-250$. 
plido los 60 años. Esta edad está fijada por decreto para esta empresa, cuyas aeronaves tienen un código de navegación aérea similar a las del Estado porque realiza "actividades confidenciales para las necesidades de los servicios secretos con fines de protección de la seguridad nacional". Durante el litigio subsiguiente al cese del trabajador, la Corte Suprema di Cassazione interroga al Tribunal de Justicia de la Unión Europea.

La primera cuestión se refiere al impacto de un punto del anexo I del Reglamento 1178/2011/UE (requisitos técnicos y procedimientos administrativos aplicables al personal de vuelo de la aviación civil) que, en determinadas condiciones, permite la continuación de los servicios de piloto hasta los 65 años. El Tribunal de Justicia observa que Italia hizo uso de una disposición del Reglamento que le autorizaba a cumplir con este anexo solo en 2013, por lo que no se aplicó a los hechos del caso y no ve necesario responder a la pregunta. Es una pena, porque podría surgir en el futuro en otros casos.

Queda por comparar las disposiciones impugnadas con la Directiva 2000/78/CE, reforzada por el artículo 21 de la Carta de los Derechos Fundamentales de la Unión, dado el precedente en el que, en un caso similar, el Tribunal de Justicia constató una discriminación contraria al artículo 2 de la Directiva (Caso Prigge y otros ${ }^{41}$ ). Se trataba entonces de un convenio colectivo alemán que imponía una edad máxima de 60 años a los pilotos de aviación civil, mientras que las normas internacionales (los hechos de aquel caso eran anteriores a la adopción del Reglamento 1178/2011) autorizaban también, en determinadas condiciones, el mantenimiento en servicio hasta los 65 años.

Sobre la base del "expediente que se le ha entregado", el Tribunal está convencido de que las "operaciones vinculadas a la seguridad nacional" que realiza la empresa en cuestión pueden tener lugar en "condiciones difíciles, incluso extremas", que exigen condiciones físicas "particularmente elevadas", aptitudes que permiten descartar la comparación con el precedente Prigge y otros. En consecuencia, el Tribunal declara que las normas impugnadas pueden ser validadas mediante dos excepciones autorizadas por la Directiva: la del artículo 2.5, relativo a las medidas necesarias para la seguridad pública previstas por la legislación nacional (a este respecto, el Tribunal contradice al Abogado General M. Szpunar, quien había señalado que las disposiciones italianas eran reglamentarias y no legales); y la del artículo 4.1, relativo a los requisitos profesionales esenciales y decisivos. Por supuesto, corresponde a los tribunales nacionales verificar, en el primer caso, si las medidas son necesarias, y en el segundo si son proporcionadas, y casi se puede oír a los jueces del Tribunal lavándose colectivamente las manos con alivio.

\subsection{Sentencia del Tribunal de Justicia de la Unión Europea de 2 de abril de 2020, C O, C-670/18}

En una convocatoria a candidatos para una misión de estudio y asesoría relacionada con su centro de reciclaje, el municipio de Gesturi (Cerdeña) aplicó un decreto-ley de 6 de julio de 2012 que prohíbe a las autoridades locales emplear a jubilados de los sectores

\footnotetext{
${ }^{41}$ Sentencia del TJUE de 13 septiembre de 2011, Prigge, Fromm y Lambach, C-447/09.
} 
tanto privado como público. Descartado por este motivo, un pensionista que reunía las demás condiciones (diploma y experiencia) denunció la discriminación directa por edad ante el Tribunale Amministrativo Regionale, que acudió al Tribunal de Justicia.

Sin pedir conclusiones a su Abogado General, el Tribunal zigzaguea por su jurisprudencia anterior ${ }^{42}$, ahora abundante, que se refiere a los "objetivos de política social" invocados por los Estados miembros en relación con el artículo 6.1 de la Directiva 2000/7/ CE: en particular, como en el caso, dar a los jóvenes más posibilidades profesionales. El Tribunal concluye que los artículos 2.2, 3.1 y 6.1 de la Directiva no se oponen a la medida impugnada, y devuelve al tribunal nacional la tarea de comprobar si es adecuada y necesaria en relación con el objetivo perseguido. Previamente, el Tribunal hace varias observaciones que parecen más aptas para reforzar las dudas del Tribunale que para disiparlas. Así las cosas, ¿los jóvenes practicantes podrán cumplir con el requisito de experiencia requerido por la misión? Además, ¿la política social invocada no choca con una política presupuestaria, plasmada en otras disposiciones, que permite encomendar funciones de dirección a los jubilados que las asumen gratuitamente?

Por analogía lejana, el caso nos recuerda una época en la que determinadas autoridades belgas adoptaron normas que, con el fin de contratar personal para sus servicios, prohibían la sobrecualificación con el fin de proteger las oportunidades de empleo de los menos cualificados. Esta idea fue abandonada cuando el Tribunal Administrativo Supremo preguntó a los empleadores públicos, demandados, cómo contratar a una persona con un título superior a los requisitos del cargo podría obstaculizar el buen desempeño del cargo ${ }^{43}$.

2.4. Sentencia del Tribunal de Justicia de la Unión Europea de 7 de febrero de 2020, T K, U L y $V M, C-773 / 18$

En nuestra crónica anterior ${ }^{44}$, habíamos apuntado que la cuestión de la antigüedad en el servicio público austriaco se había convertido en una piedra en el zapato para el Tribunal de Justicia. Mediante una especie de "Revancha por Sadowa", la misma cuestión en Alemania aumentó aún más la incomodidad causada por la piedra. En 2011, el Tribunal había decidido en Hennigs y $\mathrm{Mai}^{45}$ que utilizar el criterio de la edad para determinar qué escala salarial se asignaría a los trabajadores contratados por las instituciones públicas alemanas infringía los artículos 2 y 6, apartado 1, de la Directiva 2000/78/CE. Inmediatamente surgió una controversia ante los tribunales nacionales en cuanto a la aplicación

\footnotetext{
${ }^{42}$ Cita en particular su Sentencia de 12 de enero de 2010, Petersen, C-341/08.

${ }^{43}$ Así, las Sentencias del Tribunal Administrativo Supremo Mattys, no 89.800 de 26 de septiembre de 2000, y no 94.658 de 5 de abril de 2001; y Brouillard, $n^{\circ} 115.391$ de 3 de febrero de 2003 y n 131.418 de 13 de mayo de 2004 (www.raadvst-consetat.be). Véase también, sobre la función pública europea, la Sentencia de 28 de marzo de 1996 del Tribunal de Primera Instancia de la UE, Noonan, T-60/92, Rec., II, p. 443.

${ }^{44}$ Jean Jacqmain, “Crónica de la jurisprudencia europea sobre igualdad (De 1/9/2018 a 31/8/2019)”, Femeris, Vol. 5, no 2, pp. 252-253; a propósito de las Sentencias del TJUE de 8 de mayo de 2019, Leitner, C-396/17, y de 8 de mayo de 2019, Österreichischer Gewerkschaftsbund, C-24/17.

${ }^{45}$ Sentencia del TJUE de 8 de septiembre de 2011, C-297/10 y C-298/10, asuntos acumulados.
} 
de esta lectura al personal estatutario que el Tribunal resolvió en Specht y otros ${ }^{46}$; y luego insistió en Unland ${ }^{47}$ en relación a los magistrados.

Por su parte, la legislación nacional se había ajustado a la doctrina del Tribunal desde su primera sentencia, al sustituir el criterio de la antigüedad por el de edad, pero debía abordar de inmediato el aspecto relativo a los derechos adquiridos; en cada etapa, el Tribunal tuvo que especificar en qué medida los sistemas de conversión y las medidas de protección eran admisibles con arreglo al artículo 6, párrafo 1, de la Directiva.

Una magistrada y dos funcionarios empleados por el Land de Sajonia-Anhalt tuvieron que someter al Verwaltungsgericht (Tribunal administrativo) de Halle la disputa entre ellos y su empleador. Según el Tribunal Constitucional alemán, el estatuto pecuniario de este Land concedía a los magistrados y funcionarios una remuneración inferior al mínimo fijado por la Ley Fundamental, lo que había obligado al Land a legislar para otorgar a los interesados, a partir de 2008, una remuneración adicional. Pero esa remuneración se calculaba de acuerdo con una escala de baremación determinada por la edad, criterio que resultaba discriminatorio de acuerdo con la sentencia Hennigs y Mai. La fecha de dicho pronunciamiento se tomó entonces como el punto de partida del período de prescripción de dos meses, más allá del cual un beneficiario ya no podía reclamar el suplemento; y el Land siempre se opuso alegando prescripción respecto de las tres personas en cuestión.

Solicitado por el tribunal alemán, el Tribunal de Justicia considera en primer lugar que, dado el gran número de magistrados y funcionarios afectados por el problema y "la ausencia de un sistema de referencia válido", los artículos 2 y 6 de la Directiva pueden ser aplicables y dar cabida a la remuneración adicional, "siempre que no dé lugar a la perpetuación de una diferencia de trato en el tiempo según la edad", reserva que, en este caso, parece más bien cosmética. Por ello, teniendo en cuenta la controversia jurisprudencial mencionada, el Tribunal declara que el principio de eficacia es contrario a que la fecha de la sentencia Hennigs y Mai determine la expiración de un plazo (muy breve) de prescripción si ello impide a los interesados hacer valer un derecho derivado del Derecho de la Unión, lo cual el órgano jurisdiccional nacional debe valorar ${ }^{48}$.

2.5. Sentencia del Tribunal de Justicia de la Unión Europea de 19 de diciembre de 2019, C-460/18P

En su momento, no pudimos silenciar nuestra indignación por una sentencia ${ }^{49}$ en la que el Tribunal General de la Unión Europea se negó a conceder una pensión de supervivencia en un supuesto en el que el demandante había vivido veinte años en convivencia con una funcionaria europea que lo apoyaba debido a la grave enfermedad crónica que padecía. La pareja se casó, pero once meses después, la esposa murió.

\footnotetext{
${ }^{46}$ Sentencia del TJUE de 19 de junio de 2014, C-501/12 a 506/12, C-540/12 y C-541/12, asuntos acumulados.

${ }^{47}$ Sentencia del TJUE de 9 de septiembre de 2015, C-20/13.

${ }^{48}$ El Tribunal de Justicia cita como precedente su Sentencia de 8 de julio de 2010, Bulicke, C-246/09.

${ }^{49}$ Sentencia del Tribunal General de la Unión Europea de 3 de mayo de 2018, H.K. vs. Comisión, T-574/16; véase Jean Jacqmain, “Crónica de la jurisprudencia europea sobre igualdad (De 1/9/2017 a 31/8/2018)”, Femeris, Vol. 4, no 2, pp. 208-209.
} 
Frente a esa sentencia, el interesado recurrió ante el Tribunal de Justicia. En sus muy detalladas conclusiones sobre el recurso interpuesto por el interesado ante el Tribunal de Justicia, el Abogado General P. Pikamäe señaló que, entre otros motivos, el viudo impugnó el artículo 17 del Anexo VIII del Estatuto de los Funcionarios, que impone el requisito mínimo de un año de matrimonio, por considerarlo contrario a lo dispuesto en el artículo 21 de la Carta de los Derechos Fundamentales de la Unión, sin referirse a un criterio particular. Después de un detallado análisis, el Abogado General consideró que la comparación pertinente debía hacerse entre las parejas cuyo matrimonio había durado menos de un año; de hecho, la evolución del Estatuto de los Funcionarios permite ahora completar el año teniendo en cuenta un período inmediatamente anterior de "unión registrada", pero no de cohabitación de facto. Por tanto, según él, lo que estaba en juego era el principio general de igualdad, consagrado en el artículo 20 de la Carta. Continuando con el examen, las conclusiones constataron que la distinción excedía del objetivo perseguido y resultaba excesivamente perjudicial para las partes interesadas, especialmente en el presente caso donde se excluyó cualquier riesgo de malversación o fraude de ley dada la realidad de los hechos. Por lo tanto, la norma estatutaria debía declararse inválida en virtud del artículo 20 de la Carta.

Lamentablemente, el Tribunal no dedica una sola línea a la relevancia de este razonamiento. Es cierto que comienza por anular la sentencia del Tribunal General por considerar que su motivación es confusa y contradictoria. No obstante, cuando entra a conocer y resolver el recurso inicial contra la denegación de la Comisión a la solicitud de pensión de supervivencia, el Tribunal de Justicia vuelve de nuevo a desestimarlo, siguiendo la formulación del Estatuto. En particular, señala la asimilación de la unión registrada como una concesión suficiente de acuerdo con el desarrollo social, pero se cuida de no citar la sentencia ${ }^{50}$ en la que, sobre la reagrupación familiar (artículo 21.1 del TFUE y Directiva 2004/38/CE), señaló que había que tener en cuenta la convivencia de facto. Por lo tanto, debemos trasladar la valoración que anteriormente hicimos a la sentencia del Tribunal General, a la sentencia dictada ahora por el Tribunal de Justicia.

\section{Discriminación por razón de la discapacidad}

3.1. Sentencia del Tribunal Europeo de Derechos Humanos de 24 de octubre de 2019, J.D. y A.C. v. Reino Unido, demandas $n^{\circ} 32949 / 17$ y 34614/17. Ver supra

3.2. Sentencia del Tribunal de Justicia de la Unión Europea de 11 de septiembre 2019, D W, C-397/18

Un nuevo caso español ha mostrado al Tribunal de Justicia tan cauto como siempre ${ }^{51}$ en su aproximación al concepto de discapacidad en el sentido de la Directiva 2000/78/ CE.

\footnotetext{
${ }^{50}$ Sentencia del TJUE de 12 de julio de 2018, Banger, C-89/17.

${ }^{51}$ Ver STJUE de 18 de enero de 2018, Ruiz Conejero, Asunto C-270/16, comentada en Jean Jacqmain, “Crónica de la jurisprudencia europea sobre igualdad (De 1/9/2017 a 31/8/2018)", Femeris, Vol. 4, no 2, pp. 210-211.
} 
Una trabajadora, empleada en una fábrica de tubos de plástico, se ve afectada de epicondilitis, enfermedad reconocida como profesional. Posteriormente, sufre también un trastorno de ansiedad y ambos síndromes conjuntamente provocan ausencias repetidas. El servicio de prevención de riesgos laborales la califica de "trabajadora especialmente sensible a los riesgos laborales" conforme a la Ley 31/1995, de 8 de noviembre, de Prevención de Riesgos Laborales. Por tal motivo, es objeto de varios cambios de destino que, más tarde, la Inspección de Trabajo estima inadecuados con respecto a las particularidades propias de su estado de salud.

Para justificar los despidos por causas objetivas, como exige el Estatuto de los trabajadores, la empresa utiliza una combinación de cuatro criterios: estar asignado/a a la fabricación de tubos de plástico, presentar una productividad inferior al $95 \%$, una menor polivalencia funcional y un elevado índice de absentismo. Sobre esta base, junto a consideraciones económicas, técnicas y organizativas, la empleada es una de los diez trabajadores despedidos a lo largo del mismo período. Durante el litigio que siguió, el Jutjat Social no 3 de Barcelona se cuestiona acerca de la posible incidencia de la Directiva 2000/78/ CE y se dirige al Tribunal de Justicia.

Este responde, en primer lugar, que el estado de salud de una trabajadora reconocida como especialmente sensible a los riesgos laborales, lo que hace que se le aparte de diversas tareas, no equivale al concepto de discapacidad en el sentido de la Directiva, salvo que disminuya las posibilidades de que la interesada participe en la vida profesional como el resto de trabajadores. Este es el criterio de la Convención de las Naciones Unidas sobre los Derechos de las Personas con Discapacidad, y corresponde al órgano jurisdiccional nacional comprobar si es así.

A continuación, y en el caso de que la trabajadora en cuestión pudiera considerarse como discapacitada, el artículo 2.2.b).ii) de la Directiva lleva a analizar las razones objetivas de su empresario como causante de discriminación indirecta por discapacidad, a menos que la persona en cuestión se haya beneficiado previamente de ajustes razonables en el sentido del artículo 5. Su verificación corresponde también al órgano jurisdiccional nacional. Al respecto, el Tribunal está de acuerdo con el análisis en dos tiempos (ajustes razonables / causas objetivas) que le recomendó infructuosamente la Abogada General E. Sharpston en Ruiz Conejero.

Debemos lamentar que, en la redacción de sus cuestiones prejudiciales, el Jutjat Social no haya mencionado que, según su Exposición de Motivos, la Ley 31/1995 es el instrumento nacional que transpone la Directiva marco 89/391/CEE relativa a la promoción de la seguridad y salud en el trabajo, así como varias de sus directivas específicas. De hecho, el plan de prevención de riesgos laborales establecido en el instrumento marco exige la adopción de medidas que, en la práctica, pueden coincidir con las que se señalan como adaptaciones razonables en beneficio de los trabajadores calificados como discapacitados a efectos de la Directiva 2000/78/CE. Al no posibilitar que el Tribunal de Justicia considere la interacción de mutua de ambos conceptos contenidos en dos normas de la Unión, ello da lugar a que se pierda la oportunidad de hacer avanzar el debate general sobre la repercusión del estado de salud en el empleo. 


\section{Discriminación por razón de la orientación sexual}

\subsection{Sentencia del Tribunal de Justicia de la Unión Europea de 23 abril 2020, Associazione Avvocatura per i diritti LGBTI, C-507/18}

En Italia, un abogado había dicho en un programa de televisión que nunca contrataría en su oficina a un gay. Una asociación de abogados de defensa de los derechos de las personas LGBTI consideró tales declaraciones contrarias a la legislación antidiscriminatoria e inició un procedimiento judicial que llegó hasta el Corte Suprema di Cassazione, la cual, a la vista de las particularidades del caso, preguntó al TJUE sobre el alcance de la Directiva 2000/78/CE.

Basándose en las notables conclusiones de la Abogada General E. Sharpston, la Gran Sala del Tribunal recuerda ante todo que la libertad de expresión garantizada por el artículo 11 de la Carta de los Derechos Fundamentales de la Unión puede encontrar un límite en las condiciones previstas por el artículo 52.1. A continuación, establece que las declaraciones enjuiciadas entran dentro de la prohibición de discriminación por motivos de orientación sexual, en el sentido del artículo 2 de la Directiva, y que, si bien nadie ha sido víctima de aquella puesto que el despacho de abogados del autor de las mismas no procedió en el momento de su emisión a realizar ningún contrato, estas declaraciones pueden poner en entredicho las "condiciones de acceso al empleo" mencionadas en el artículo 3. El tribunal nacional debe, no obstante, garantizar que el vínculo entre este concepto y la política de contratación de la empresa no es puramente hipotético.

Sobre este último aspecto, debemos repetir la observación que hicimos en relación con la sentencia Achbita ${ }^{52}$ : remitir el examen de los elementos fácticos al tribunal que formuló la cuestión preliminar suscita dudas cuando este último no tiene tal competencia en virtud de su legislación nacional. En el caso Achbita, el Tribunal de Casación belga censuró la sentencia del Tribunal Laboral de Amberes, objeto de recurso; pero esta solución no siempre es accesible si el Tribunal Supremo no tiene motivos según el derecho interno para casar la resolución de la instancia inferior.

La segunda cuestión se refería a la conformidad de la legislación nacional que faculta a una asociación a emprender acciones para constatar una discriminación y reclamar una indemnización. El Tribunal de Justicia responde que la Directiva 2000/78/CE no se opone a ese mecanismo de eficacia, pero se trata de una cuestión que debe determinar el Estado miembro. Se limita a citar su sentencia ACCEPT (STJUE de 25/07/2007, C-81/12), ciertamente dedicada a comentarios homófobos, pero no la sentencia Feryn (STJUE de 10/07/2008, C-54/07), sobre cuestiones de origen étnico, aunque sus circunstancias eran más próximas al caso italiano.

${ }^{52}$ STJUE de 14/03/2017, C-157/15, que se refería a convicciones religiosas; véase la crónica de Jean Jacqmain en Journal de Droit Européene, 2017, p. 377 (no traducida en esta parte). 


\section{Discriminaciones más allá del marco general}

5.1. Sentencia del Tribunal Europeo de Derechos Humanos de 17 de septiembre de 2019, Iovcev e.a. c. Moldavia y Rusia, Demanda n 40942/14

Señalar brevemente que una vez más el Tribunal Europeo de Derechos Humanos se ha enfrentado a denuncias sobre la presión y el acoso que sufren, en la llamada "República Moldava de Transnistria", tanto las escuelas que, a pesar de la prohibición legal, persisten en enseñar en moldavo y caracteres latinos, como los alumnos que asisten a ellas y sus padres. El Tribunal declaró, contra la Federación Rusa, varias violaciones del artículo 2 del Primer Protocolo (derecho a la educación) y de los artículos 5 (prisión arbitraria) y 8 (vida privada y familiar) de la C.E.D.H.; a diferencia de un caso anterior ${ }^{53}$, los demandantes no habían invocado el artículo 14. A algunos les concedieron $12.000 €$, a otros 6.000 en concepto de daños morales.

\subsection{Sentencia del Tribunal Europeo de Derechos Humanos 31 octubre 2019, Papageorgiou a.o. c. Grecia, Demanda $n^{\circ} 4762 / 18$ y $6140 / 18$}

Como en el caso anterior, tampoco se planteó la dimensión de la discriminación en las solicitudes de los padres de alumnos que asisten a la escuela en dos pequeñas islas griegas. La legislación exige que, para obtener la exención de la asignatura de religión ortodoxa para sus hijos, los padres deben declarar solemnemente que sus hijos, y por tanto implícitamente ellos mismos, no se adhieren a esa confesión. Observando, entre otras cosas, el riesgo de estigmatización en comunidades insulares muy pequeñas, así como la ausencia de la asignatura alternativa prevista por la ley ${ }^{54}$, la Corte de Estrasburgo consideró que existía una violación del artículo 2 del Primer Protocolo (derecho a una educación acorde con las convicciones de los padres) leído a la luz del artículo 9 de la CEDH (libertad de conciencia y de expresión) ${ }^{55}, \mathrm{y}$ concedió a cada uno de los demandantes 2.000 euros en concepto de daños morales.

5.3. Sentencia del Tribunal Europeo de Derechos Humanos de 16 de junio de 2020, Ince c. Turquía, Demanda ${ }^{\circ}$ 52772/08

El Tribunal de Estrasburgo también se encontró, tardíamente, con una versión masculina (pero algo ridícula) del caso Leyla Şahin c. Turquía ${ }^{56}$ : en 1998, las decisiones de prohibición adoptadas por las autoridades universitarias contra los estudiantes con velo

\footnotetext{
${ }^{53}$ Sentencia del Tribunal Europeo de Derechos Humanos de 19 octubre 2012 (Gran Sala), Catan e.a. c. Moldavia y Rusia, Demanda no 43370/04, 8252/05 y 18454/06.

${ }^{54}$ Estos dos aspectos (libertad de conciencia y expresión) habían sido tomados en cuenta en un caso relativamente similar que cita el Tribunal: Sentencia de 15 de junio de 2010, Grzelak c. Polonia, Demanda n 7710/02.

${ }^{55}$ En este mismo orden de ideas, el Tribunal señaló una violación del artículo 9 con respecto a una práctica de ciertos registradores que, al emitir un certificado de nacimiento, hicieron una mención reveladora de la ausencia de bautismo (Sentencia de 25 de junio de 2020, Stavropoulos a.o. c. Grecia, Demanda n 52484/18).

${ }^{56}$ Sentencia del TEDH de 10 de noviembre de 2005 (Gran Sala), Leyla Şahin c. Turquía, Demanda no 44774/98.
} 
también afectaron a un estudiante médico que afirmó llevar barba por motivos religiosos. El litigio que siguió duró diez años sin darle satisfacción. A pesar de ello, terminó sus estudios y ahora trabaja como jefe de departamento de un hospital público. Sin embargo, denunció violaciones de los artículos 8 y 10 (libertad de expresión) de la CEDH y 2 del Primer Protocolo, sin citar el artículo 14 de la CEDH. El Tribunal se refiere a un precedente similar ${ }^{57}$ y se limita a examinar la consistencia de las denuncias y los hechos presentados; el informe señala que, durante sus estudios, el estudiante se había acortado la barba, por lo que su abogado podría haberle malinterpretado y argumentado ante los tribunales nacionales que el pelo no tenía importancia religiosa. Doce años después de la interposición de la petición, el Tribunal por unanimidad la declaró inadmisible.

5.4. Sentencia del Tribunal Europeo de Derechos Humanos de 26 de mayo de 2020, Hakim Aydın c. Turquía, Demanda ${ }^{\circ} 4048 / 09$

Una vez más ${ }^{58}$, las reclamaciones sobre el uso del idioma kurdo en la educación han llegado al Tribunal Europeo de Derechos Humanos. En 2008, un estudiante fue puesto en prisión preventiva por participar en una sentada pacífica en las instalaciones de la Universidad de Diyarbakir, lo que habría constituido un delito de obstrucción a la educación. El Tribunal de Estrasburgo consideró que se habían violado los artículos 5 (privación de libertad) y 11 (manifestación) de la CEDH, pero, curiosamente, no puede encontrar ningún elemento que permita aplicar el artículo 14. El demandante obtiene 5.000 euros en concepto de daños morales.

\subsection{Sentencia del Tribunal Europeo de Derechos Humanos de 24 de marzo de 2020, Cegolea c. Rumanía, Demanda ${ }^{\circ} 25560 / 30$}

Según la legislación rumana sobre minorías nacionales, la comunidad italiana tiene derecho a un escaño en el parlamento. Solo las organizaciones reconocidas como de utilidad pública pueden presentar candidatos a las elecciones. Un cambio legislativo y una diferencia de interpretación entre las administraciones interesadas había impedido a una candidata presentarse, sin obtener reparación judicial. A propósito de su demanda, la Corte Europea concluyó que la organización a la que ella pertenecía había sido tratada de forma desfavorable en comparación con las que representan a otras minorías nacionales, una violación del artículo 14 de la CEDH (origen étnico) combinado con el artículo 3 del Primer Protocolo (derecho a elecciones libres). Este veredicto proporciona una satisfacción justa por el daño infligido.

\footnotetext{
${ }^{57}$ Sentencia del TEDH de 24 de mayo de 2005, Tiğ c. Turquía, Demanda n 8165/03.

${ }^{58}$ Ver también la Sentencia del TEDH de 12 de diciembre de 2017, Çölgeçen e.a. c. Turquía, Demanda n 50124/07, comentada en Jean Jacqmain, “Crónica de la jurisprudencia europea sobre igualdad (De 1/9/2017 a 31/8/2018)", Femeris, Vol. 4, no 2, pp. 214-215.
} 
5.6. Sentencia del Tribunal Europeo de Derechos Humanos de 5 de mayo de 2020, Csiszer y Csibi c. Rumanía, Demanda $n^{\circ} 71314 / 13$ y 68028/14

En 1919, la guerra rumano-húngara, entre otras, había sacado a la luz la "cuestión de las nacionalidades", que todavía hoy está mal resuelta. Las personas que afirman ser de la minoría Szeker (Sicula) querían realizar una manifestación en Cluj-Napoca, en el Día Nacional de Rumania, para conmemorar un episodio marcial húngaro en este conflicto. Al haber infringido la prohibición de organizarlo, dos de ellos fueron objeto de sanciones administrativas y los litigios resultantes los llevaron ante el Tribunal de Estrasburgo. Este último considera que la disposición legal que prohíbe este tipo de iniciativas está adecuadamente justificada por las autoridades nacionales, de manera que la injerencia en la libertad de reunión (artículo 11 de la C.E.D.H.) no fue excesiva. Sin embargo, se puede considerar que el Tribunal se apresuró a desestimar la alegación de discriminación por motivos de origen étnico (artículo 14).

El pasado año judicial ha supuesto tanto un estímulo como una decepción para las víctimas de discriminaciones, así como para los profesionales en la materia. Y releyendo la observación final que realizamos con ocasión de la crónica 2018/201959, constatamos de nuevo que las distintas jurisdicciones (y otras instituciones) europeas, aunque actúan en paralelo, no interactúan casi nada.

\footnotetext{
${ }^{59}$ Jean Jacqmain, “Crónica de la jurisprudencia europea sobre igualdad (De 1/9/2018 a 31/8/2019)", Femeris, Vol. 5 , no 2, p. 262. Allí calificábamos la interacción entre TJUE y TEDH como "siempre aleatoria y reticente”.
} 